UNIVERSITE DE LAUSANNE - FACULTE DE BIOLOGIE ET DE

MEDECINE

HOPITAL OPHTALMIQUE JULES GONIN

SERVICE D'OPHTALMOLOGIE

\title{
TEN YEARS FOLLOW-UP AFTER DEEP SCLERECTOMY WITH COLLAGEN IMPLANT
}

THESE

préparée sous la direction du Professeur associé André Mermoud

et présentée à la Faculté de biologie et de médecine de

l'Université de Lausanne pour l'obtention du grade de

DOCTEUR EN MEDECINE

290

Bis

\author{
par \\ Alexandre BISSIG \\ Médecin diplômé de la Confédération Suisse \\ BHTE 3504 \\ Originaire de Isenthal (URI)
}

Lausanne

2008 


\section{Rapport de synthèse}

\section{BUT}

Le but de ce sujet de recherche est d'évaluer le taux de succès et les complications à long terme de la sclérectomie profonde non pénétrante avec implant de collagène (SPIC) chez les patients atteints de glaucome à angle ouvert.

\section{METODES ET PATIENTS}

Il s'agit d'une étude clinique, prospective, monocentrique, non-randomisée, effectuée sur 105 patients atteints d'un glaucome à angle ouvert médicalement non-contrôlé. Ces patients ont tous bénéficiés d'une SPIC, effectuée selon le geste chirurgicale standard (technique décrite dans l'article). Dans le cadre de cette étude, nous avons effectué un bilan ophtalmologique complet avant l'acte chirurgical puis un suivi postopératoire à 1 et 7 jours ; 1,2,3,6,9,12 mois et ensuite tous les 6 mois durant les dix années suivantes.

\section{RESULTATS}

Le suivit moyen de cette étude s'étend sur 101.5 \pm 43.1, [3-144] mois ( moyenne \pm écart type, [étendue]). La pression intraoculaire (PIO) préopératoire était élevée à $26.8 \pm 7.7$, [14-52] $\mathrm{mmHg}$, et l'acuité visuelle corrigée à $0.71 \pm 0.33,[0.02-1.5]$. Au terme des dix années après le traitement chirurgical, le nombre de patients suivit était de 52 avec une pression intraoculaire abaissée à $12.2 \pm 4.7,[6-20] \mathrm{mmHg}$ et une acuité visuelle corrigée de $0.63 \pm 0.34,[0.01-1.2]$. Le nombre de médicaments par patient a diminué de $2.3 \pm 0.7$, [1-4] à $1.3 \pm 1.1$, [0-3].

Dix ans après la SPIC, une pression intraoculaire $\leq 21 \mathrm{mmHg}$ sans médicaments (succès complet) était obtenue chez $47.7 \%$ des patients et $89 \%$ avec ou sans traitement médicamenteux (succès relatif). Les gestes postopératoires additionnels par gonioponcture ont été effectués sur 61 yeux (59.8\%) et les injections sous-conjonctival de 5-fluorouracil ont été pratiquées sur 25 yeux dont 5 incluant un needling.

\section{CONCLUSIONS}

Le suivit à long terme sur une période de dix ans, démontre que la sclérectomie profonde avec implant de collagène (SPIC) est efficace dans le contrôle de la pression intraoculaire et présente peu de complications postopératoires. 


\title{
Ten years follow-up after deep sclerectomy with
}

\section{collagen implant}

\author{
Alexandre Bissig, $\mathrm{MD}^{*},{ }^{1}$ Delphine Rivier, $\mathrm{MD} ;{ }^{1}$ Marc Zaninetti, $\mathrm{MD}, \mathrm{PhD}{ }^{1}$ \\ Tarek Shaarawy, MD, MSc ;', 2 André Mermoud, MD; ${ }^{3}$ Sylvain Roy, MD, \\ $\mathrm{PhD}^{*}{ }^{1}$ \\ *: These authors have equally contributed to this work. \\ 1: Jules Gonin Eyes Hospital, Glaucoma Unit, Lausanne University, Lausanne, Switzerland. \\ 2: Ophthalmology Clinic, Department of Clinical Neurosciences, Geneva University \\ Hospitals, Geneva, Switzerland. \\ 3: Glaucoma Center, Clinique de Montchoisy, Lausanne, Switzerland
}

Address for correspondence:

Sylvain Roy, MD, $\mathrm{PhD}$

Jules Gonin Eyes Hospital

Glaucoma Unit

Lausanne University

Av, de France 15

CH-1004 Lausanne

Switzerland

Tel. +41216268224

Fax +41216268246

E-mail: sylvain.roy@epfl.ch 


\begin{abstract}
Purpose:

To evaluate the long term success rate and complications of non penetrating deep sclerectomy with collagen implant (DSCI) in open-angle glaucoma.
\end{abstract}

\title{
Patients and Methods:
}

Clinical, prospective, monocentric, non-randomized, unmasked study on 105 patients with medically uncontrolled glaucoma. A standard procedure DSCI was performed. Complete examinations were performed before surgery and postoperatively at 1 and 7 days; 1, 2, 3, 6, 9, 12 months and then every 6 months during the 10 following years.

\section{Results:}

The mean follow-up was $101.5 \pm 43.1,[3-144]$ months (mean $\pm \mathrm{SD}$, [range]). The preoperative intraocular pressure (IOP) was $26.8 \pm 7.7,[14-52] \mathrm{mmHg}$ and the best corrected visual acuity (BCVA) $0.71 \pm 0.33,[0.02-1.5]$. Ten years after surgery IOP was $12.2 \pm 4.7$, [6$20] \mathrm{mmHg}$ and BCVA $0.63 \pm 0.34,[0.01-1.2]$ (number of remaining patients $=52$ ). The mean number of medications per patient went from $2.3 \pm 0.7,[1-4]$ down to $1.3 \pm 1.1,[0-3]$. An IOP $\leq 21 \mathrm{mmHg}$ without medication was achieved in $47.7 \%$ patients and in $89 \%$ with or without treatment. One major complication was reported. Goniopuncture was performed in 61 eyes (59.8\%), 5-fluorouracil treatment given to 25 patients postoperatively and included needling $(n=5)$.

\section{Conclusions:}

Based on a 10 year follow-up deep sclerectomy with collagen implant demonstrated its efficacy in controlling IOP with few postoperative complications. 


\section{Key words:}

glaucoma - glaucoma drainage implant - filtering surgery 


\section{Introduction}

Deep sclerectomy with collagen implant (DSCI) is a non-penetrating filtration procedure used for the surgical treatment of medically uncontrolled open-angle glaucoma. It was first described by Fyodorov et al in 1989. 'It was conceived in an attempt to lower the incidence of early postoperative complications of conventional trabeculectomy (such as hypotony, hyphema, flat anterior chamber, choroidal detachment, choroidal effusion or hemorrhage, surgery-induced cataract and endophthalmitis) ${ }^{2-8}$, without compromising on the success rate of intraocular pressure (IOP) reduction. ${ }^{9-11}$

Medium term studies of this surgical procedure have already been reported in our previous reports. ${ }^{12-14,25}$ In this study we present the long-term results (10 years) of DSCI. The IOP control, the rate of complications and the reduction of glaucoma treatment for the initial 102 patients were studied. 


\section{Patients and Methods}

\section{Case selection}

This clinical, prospective, monocentric, non-randomized, unmasked study was performed on 105 eyes of 105 patients with open-angle glaucoma. All operations were performed by the same surgeon (A.M). Surgeries were performed between June 1994 and January 1997. These were the initial patients who underwent DSCI for this diagnosis at the Jules Gonin Eyes Hospital in Lausanne, Switzerland.

Inclusion criteria were: medically uncontrolled primary open-angle, pseudoexfoliative, pseudophakic, normal tension, pigmentary, aphakic, traumatic and open angle uveitic glaucomas (table 1). Medically uncontrolled glaucoma was defined as an IOP higher than 21 mmHg under a maximal tolerable glaucoma therapy with evidence of progression of visual fields defects and or optic nerve cupping. Previous ocular surgery such as filtering or cataract extraction was not a criterion for excluding patients from this study. Exclusion criteria were: angle-closure, neovascular, congenital or juvenile glaucomas, known allergy to porcine collagen, previous argon laser trabeculectomy or eye surgery within 6 months prior to enrollment in the study, unwillingness to participate in the study, and pregnant or breast feeding women. Patients with operative perforation of the trabeculo-Descemet's membrane were purposely removed from this study.

The study was approved by the Ethics Committee of the University of Lausanne. Every patient gave written informed consent before surgery. None of the authors have any financial interest in the study.

\section{Preoperative examination}


The data were obtained from the medical records of the patients. Every patient underwent complete ophthalmic examination that included best corrected visual acuity (BCVA) measured at 6 meters on Snellen's chart, biomicrosopy, Goldmann applanation tonometer IOP measurements, anterior chamber angle assessment using a 4 mirrors contact lens, and fundus examination. The visual fields were tested using the Octopus 123 program G1 (Interzeag AG, Schlieren, Switzerland).

\section{Postoperative follow-up}

Postoperative evaluation which included all preoperative examinations except for the visual fields were performed at 1 and 7 days; 1, 2, 3, 6, 9, 12 months and then every 6 months thereafter to complete a 10 years follow-up. The visual field examination was repeated every year. Complications are defined on table 3. Mains outcomes were the IOP, the BCVA, the number of medications, and the nature and rates of complication.

\section{Surgical technique}

All surgeries were performed under retrobulbar anesthesia. The technique has been described in details elsewhere. ${ }^{12}$ Briefly a superficial scleral flap was created. A deep scleral flap dissected down to the Schlemm's canal and a trabeculo-Descemet's membrane was performed. The inner wall of Schlemm's canal was peeled off and a collagen implant sutured in the deep scleral bed. The superficial scleral flap was repositioned over the implant and secured with 2 untight sutures (Figure 1 A-F).

Postoperatively patients were treated with topical $6000 \mathrm{U} / \mathrm{ml}$ polymyxin, $0.35 \%$ neomycin and $0.1 \%$ dexamethasone tid for 4 weeks and with topical fluorometholone 1 $\mathrm{mg} / \mathrm{ml}$ tid for 3 months thereafter. 


\section{Glaucoma collagen implant}

The collagen implant is a cylindrical device (length: $2.5 \mathrm{~mm}$; diameter: $1 \mathrm{~mm}$ ) made from lyophilized porcine scleral collagen ${ }^{12}$ (Aquaflow (B) Staar Surgical AG, Nidau, Switzerland). This bio-compatible material is not known to induce systemic immunologic reactions. ${ }^{15}$ Acting as a space maintainer after hydration the implant is progressively degraded roughly 6 to 9 months after surgery. ${ }^{16,17}$

\section{Additional procedures}

The additional procedures are reported on table 2 and were indicated based on the clinical aspect of the filtering bleb. Laser goniopuncture (Microruptor II; Lasag AG, Thun, Switzerland) in Q-switch mode (5 to $8 \mathrm{~mJ}$ ) creates microscopic holes in the trabeculoDescemet's membrane allowing a direct passage of aqueous humor from the anterior chamber to the intra-scleral space. This procedure transforms a non-penetrating filtration procedure into a penetrating one. ${ }^{18,19}$ After laser treatment, topical prednisolon acetate $1 \%$ was administered tid for three days. Glaucoma medications was reintroduced when IOP $>18$ mmHg.

\section{Success rate}

Surgery was considered as a complete success when IOP was $\leq 21 \mathrm{mmHg}$ without glaucoma medication at last follow-up, as a qualified success when IOP was $\leq 21 \mathrm{mmHg}$ including medication. It was defined as a failure when IOP was $<6 \mathrm{mmHg}$ or $>21 \mathrm{mmHg}$ despite glaucoma medication, the eye required further glaucoma drainage surgery, developed phtisis bulbi, or lost light perception.

\section{Statistical analysis}


Results were analyzed using the Student's $t$ test for comparison of means, chi-square analysis for $2 \times 2$ tables, and Kaplan-Meier survival curves for long term success rate analysis. $\mathrm{P}$ was considered significant when $<0.05$. 


\section{Results}

One hundred and five eyes from 105 patients were enrolled in the study. The mean age of the patients at the time of surgery was 68.0 years $\pm 12.6,[43-102]$ (mean $\pm \mathrm{SD},[$ range]), and 21 patients (20\%) had previous ocular surgeries. The mean follow-up was $101.5 \pm 43.1$, [3-144] months and the median was 120 months. During the study 29 patients died, while 24 were lost of follow-up. Preoperative diagnoses are presented on table 1.

Mean preoperative IOP was $26.8 \pm 7.7,[14-52] \mathrm{mmHg}$, mean postoperative IOP at 1 day was $5.1 \pm 3.3,[0-15] \mathrm{mmHg}$ (reduction from preoperative value of $80.9 \%$ ), at 3 months $12.3 \pm 3.7,[5-27] \mathrm{mmHg}(-54.1 \%)$, at 3 years $13.3 \pm 3.7,[6-24] \mathrm{mmHg}(-50.4 \%)$, at 5 years $12.5 \pm 3.6,[6-21] \mathrm{mmHg}(-53.4 \%)$, at 8 years $11.9 \pm 3.9,[4-21] \mathrm{mmHg}(-55.6 \%)$ and at 10 years $12.2 \pm 4.7,[6-20] \mathrm{mmHg}(-54.5 \%)$. Figure 2 shows a steep reduction in IOP on the first postoperative day that gradually stabilized through the first month at around $12 \mathrm{mmHg}$. The mean IOP remained at that level for the next 10 years, with concurrent medication when necessary.

The mean number of medications per patient went from a preoperative value of $2.3 \pm$ $0.7,[1-4]$ down to $1.3 \pm 1.1,[0-3]$ at last follow-up, representing a reduction of $43.5 \%$. This reduction was more pronounced shortly after surgery but showed slow and gradual increase overtime (Figure 3). At 120 months and without antiglaucoma medication $47.7 \%$ of patients had an IOP $<21 \mathrm{~mm} \mathrm{Hg}$ and $43.2 \%$ achieved an IOP $<15 \mathrm{mmHg}$. With medication, $88.9 \%$ and $85.6 \%$ of the patients achieved the same targets, respectively.

Based on cumulative survival curve the success rate at 10 years was $44.6 \%$ and 77.6 $\%$ for complete and qualified success, respectively (Figure 4). One patient was defined as a failure due to IOP $>21 \mathrm{mmHg}$ (mean IOP $22.5 \mathrm{mmHg}$ ) that was stabilized with medication. Eighteen patients had failed procedure and required further glaucoma drainage surgery. This second deep sclerectomy was performed on average 60.4 months [ 1 month-10 years] after the 
initial DSCI. These patients were then all well controlled after the second procedure (IOP at 10 years: $12.6 \pm 3.7,[8-15] \mathrm{mmHg}$ ).

The BCVA decreased on the first postoperative day from $0.71 \pm 0.33,[0.02-1.5]$ (preoperatively) to $0.53 \pm 0.28,[0.02-1.25]$. It returned just below preoperative level during the first month after surgery and remained stable for the following 10 years (Figure 5). When lens opacities induced a drop in BCVA, cataract extraction was proposed and performed during the follow-up $(n=42)$.

Preoperatively mean defect and corrected lost variance were $13.1 \pm 7.4,[0.2-29]$ [dB] and $45.0 \pm 35.0,[1.4-149]\left[\mathrm{dB}^{2}\right]$, respectively, and went to $9.1 \pm 6.8,[0.1-18][\mathrm{dB}]$ and $36.8 \pm$ $27.9,[0.5-110]\left[\mathrm{dB}^{2}\right]$, respectively, 10 years later.

There was only one significant complication during surgery that consisted in a malignant glaucoma due to ciliary bloc. This complication was treated with cycloplegia medication, the IOP at the end of the follow-up period was $11 \mathrm{mmHg}$. Table 3 shows the postoperative complications. Minor complications such as transient ( $<5$ days) hypotony, limited filtering bleb leakage, and subtle choroidal detachment were not comparable in respect to severity with the long-term trabeculectomy-related complications such as prolonged shallow or flat anterior chamber, surgery-induced cataract, or bleb-related endophthalmitis.

Twenty-five patients $(24.5 \%$ ) required subconjunctival 5-FU injections to treat bleb fibrosis or encapsulation. The mean number of injections per patients was $2.9 \pm 1.9,[1-7]$ and the mean time between DSCI and injection was $1.8 \pm 2.6,[0.25-12]$ months. From these 25 patients, $5(4.9 \%)$ had additional procedures, such as needling $(n=5)$, to treat encysted blebs. No needling alone was performed without 5-FU injection.

Goniopuncture with the Nd:YAG laser was performed in 61 patients $(59.8 \%)$. The mean number of goniopunctures per patient was $1.1 \pm 0.4,[1-3]$. Delay between DSCI and 
goniopuncture was ranging from 1 to 119 months, with the median at 29 months. The mean IOP before goniopuncture was $19.8 \pm 5.5,[14-46] \mathrm{mmHg}$. The IOP decreased to $12 \pm 6.4,[5-$ 20] $\mathrm{mmHg} 15$ minutes after laser treatment, thus representing a $39.4 \%$ IOP reduction.

For the assessment of success, patients undergoing either 5-FU and/or needling and/or $\mathrm{Nd}: Y A G$ goniopuncture were considered a failure only if the IOP after such additional procedures was not lowered $<21 \mathrm{mmHg}$. 


\section{Discussion}

Trabeculectomy is a penetrating filtration surgery widely used for the surgical treatment of medically uncontrolled glaucoma. The penetrating nature of this procedure leads to several postoperative complications such as hypotony, hyphema, flat anterior chamber, choroïdal detachment, choroïdal effusion or hemorrhage, endophthalmitis and surgeryinduced cataract. Even with a modified trabeculectomy ${ }^{20}$ the predictability of the first day IOP is variable and additional procedures may have to be performed (e.g. laser suture lyses, injection of viscoelastics in the anterior chamber, needling, releasable sutures). In an attempt to lower the incidence of such complications, non-penetrating filtration surgery was developed. ${ }^{1,21}$ DSCI allows a progressive filtration of aqueous through the thin remaining trabeculo-Descemet's membrane into the intrascleral reservoir. In their ultrasound biomicroscopy study, Chiou et al ${ }^{16,17}$ speculated that aqueous, shunted into this intrascleral room, was filtered to the subconjunctival and scleral space, then eventually through the thin remaining scleral wall and into the suprachoroidal space, which offers 2 new aqueous outflow mechanisms compared to trabeculectomy. To enhance filtration and to prevent the collapse of the intrascleral space Koslov et al ${ }^{21}$ proposed the use of a collagen implant placed within the scleral bed. Similarly, Sanchez et al ${ }^{22}$ and Shaarawy et al ${ }^{26,27}$ confirmed that the surgical outcome was better when the deep sclerectomy was performed with the insertion of a collagen implant.

The major advantage of DSCI over standard trabeculectomy is the non-perforation of the anterior chamber, allowing a progressive decrease in IOP, thus lowering the occurrence of complications often seen after trabeculectomy. In an experimental model, Vaudaux et al ${ }^{23}$ studied the aqueous dynamics through the remaining thin trabeculo-Descemet's membrane and found that the outflow resistance was significantly lower low but still sufficient to control a progressive filtration and thus to avoid the trabeculectomy-related postoperative 
complications. This surgery requires a good surgical skill and the long-term results might differ depending on the surgeon's talent. The main difficulty lies in performing the dissection of the deep sclera and avoiding perforation of the thin trabeculo-Descemet's membrane. In this series, perforation of the membrane occurred in 3 patients that were not included in the study. In cases of perforation into the anterior chamber, DSCI was converted into trabeculectomy. Sanchez et al. ${ }^{24}$ reported that in this particular condition the success rate and complications were similar to that of trabeculectomy.

Short, medium-term successes of DSCI have been reported to be favorable. Based on the same patient database, Karlen et al ${ }^{12}$ reported a $55.4 \%$ IOP reduction 3 months after DSCI and $53.2 \%$ at 3 years, the mean number of medications per patient being reduced by 90 $\%$. Demailly et al ${ }^{11}$ reported a complete success rate of $89 \%$ at 6 months and $97 \%$ with or without glaucoma medication. Shaarawy et al ${ }^{13}$ demonstrated that DSCI was reaching, 5 years after surgery, a $61.9 \%$ complete success. Mermoud et al ${ }^{28}$ have compared the results after DCSI with a match group after trabeculectomy. At 24 months, they concluded that the success rate of DSCI may be comparable to that of trabeculectomy, with fewer complications. Similar conclusions were presented by El Sayyad et al ${ }^{29}$ while Chiselita ${ }^{30}$ was reporting that trabeculectomy lowers the IOP more than the NPDS technique. However, the complication rate seems to be lower in NPDS. In a comparative study with DSCI on one eye and trabeculectomy in the other eye Ambresin et al ${ }^{10}$ reported similar success rates with both procedures. Complications rates were significantly lower with DSCI than with trabeculectomy. However, additional procedures such as 5-FU injection or goniopuncture were more frequently performed in the DSCI group. To compare the effect of such additional procedure, Cillino et al $^{31}$ have compared the long-term effects of low-dosage mitomycin C (MMC) in both deep sclerectomy and trabeculectomy. At the 48 months end-point either 
procedure controlled IOP efficaciously, a low-dosage MMC can be considered a mild enhancement of deep sclerectomy IOP-lowering effect.

This paper presents the first study with a 10 year follow-up after DSCI. Our results indicate that DSCI remains a long-term successful procedure in stabilizing the IOP with low postoperative complication rates and a rather stable visual acuity. These outcomes confirm, on a long-term perspective, the results from previous papers in respects to efficacy and rate of complications compared to trabeculectomy. ${ }^{10-13,28-31}$ In this context the reduced complication rates would present some benefice in preventing further sight degradation in eyes with significant glaucoma damages, and in reducing the duration, costs and extension of the postoperative managements. The DSCI shall be considered, in that respect, as a safer technique compared to trabeculectomy, and we shall advocate this surgery when a filtering procedure is indicated in eyes at high risks for sight threatening complications.

In addition the visual field also remained stable for the majority (63\%) of patients. When comparing the results at 96 months in Shaarawy study ${ }^{25}$, reporting a $57 \%$ complete success rate, with our $47 \%$ success at 10 years, we have to take into account some elements. Seven patients had a failure at a mean of 109 months after surgery. Seven other patients died and 2 other were lost of follow up before the 10 years outcome. In a study on 436 patients with a mean age of 71.1 years, Sharma found that $29.8 \%$ of the patients with glaucoma died within 10 years of diagnosis. ${ }^{32}$ This figure compares with the $27.6 \%$ of mortality reported in this study. One of the problems mentioned by Sharma about published studies on the longterm outcome of chronic glaucoma is that they are undertaken on patients who are recruited from the practices of glaucoma subspecialists whose patient profile tends to be skewed in the direction of difficult cases and include those with advance disease. The Kaplan-Meier curve that is generally used to demonstrate progression over time should therefore be interpreted in such cases with caution. ${ }^{32}$ Altogether these long term events might explain the decrease in 
success when analyzing the surgical results on patients from the same database for 5,8 and 10 years follow up.

In conclusion, DSCI offers satisfactory results after 10 years of follow-up in controlling IOP in patients with primary and secondary open-angle glaucoma. The success rates were comparable with other filtration techniques while the immediate postoperative complication rates were low, and visual acuity remaining fairly stable. However, careful postoperative examinations are required to early recognize and treat bleb fibrosis or encapsulation with 5-FU injection or needling, as well as to identify and treat an increased outflow resistance through the trabeculo-Descemet's membrane by performing a goniopuncture. Our results indicate that DS is a viable option for the surgical therapy of openangle glaucoma. 


\section{Acknowledgements}

We thank M. Tyler Thacher from the Lausanne Swiss Federal Institute of Technology for carefully reading and correcting the paper. The study was supported by the Swiss National Science Foundation, grant \# 3200BO-103603/1. 


\section{References}

1. Fyodorov SN. Non penetrating deep sclerectomy in open-angle glaucoma. Eye Microsurgery (in Russian). 1989;52-55.

2. Watson PG, Jakeman C, Ozturk M, et al. The complications of trabeculectomy (a 20-year follow-up). Eye 1990;4:425-438.

3. Stewart WC, Shields MB. Management of anterior chamber depth after trabeculectomy. Am J Ophthalmol 1988;106:41-44.

4. Kao SF, Lichter PR, Musch DC. Anterior chamber depth following filtration surgery. Ophthalmic Surg 1989;20:332-336.

5. Brubaker RF, Pederson JE. Ciliochoroidal detachment. Surv Ophthalmol 1983;27:281-289.

6. Ruderman JM, Harbin TS Jr, Campbell DG. Postoperative suprachoroidal hemorrhage following filtration procedures. Arch Ophthalmol 1986;104:201-205.

7. Gressel MG, Parrish RK II, Heuer DK. Delayed nonexpulsive suprachoroidal hemorrhage. Arch Ophthalmol 1984;102:1757-1760.

8. Freedman J, Gupta M, Bunke A. Endophthalmitis after trabeculectomy. Arch Ophthalmol 1978;96:1017-1018.

9. Mermoud A, Schnyder CC, Sickenberg M, et al, Comparison of deep sclerectomy with collagen implant and trabeculectomy in open-angle glaucoma. J Cataract Refract Surg $1999 ; 25: 323-331$.

10. Ambresin A, Shaarawy T, Mermoud A. Deep sclerectomy with collagen implant in one eye compared with trabeculectomy in the other eye of the same patient. J Glaucoma 2002;11:214220.

11. Demailly P, Jeanteur-Lunel MN, Berkani M, et al. Non penetrating deep sclerectomy associated with collagen device in primary open-angle glaucoma. Middle-term retrospective study. J Fr Ophthalmol 1996;19,11:659-666.

12. Karlen ME, Sanchez E, Schnyder CC, et al. Deep slerectomy with collagen implant: medium term results. Br J Ophthalmol 1999;83:6-11. 
13. Shaarawy T, Karlen M, Schnyder CC, et al, Five-years results of deep sclerectomy with collagen implant. J Cataract Refract Surg 2001;27:1770-1778.

14. Hamel M, Shaarawy T, Mermoud A. Deep sclerectomy with collagen implant in patients with glaucoma and high myopia. J Cataract Refract Surg 2001;27:1410-1417.

15. Nguyen C, Boldea RC, Roy S, et al. Outfow mechanisms after deep sclerectomy with two different designs of collagen implant in an animal model. Graefes Arch Clin Exp Ophthalmol. 2006;Apr.5.[Epud ahead of print]

16. Chiou AGY, Mermoud A, Hédiguer SEA, et al. Ultrasound biomicroscopy of eyes undergoing deep sclerectomy with collagen implant. Br J Ophthalmol 1996;80:541-544.

17. Chiou AGY, Mermoud A, Underdahl JP, et al. An ultrasound biomicroscopic study of eyes after deep sclerectomy with collagen implant. Ophthalmology 1998;105:746-750.

18. Mermoud A, Karlen ME, Sickenberg M, et al. Nd-Yag goniopuncture after deep sclerectomy with collagen implant. Ophthalmic Surg Lasers 1999;30:120-125.

19. Schnyder CC. Gonioponcture. In: Schnyder CC et Mermoud A, eds. Glaucome. Paris. Elsevier; 2005:368-371.

20. Jones E, Clarke J, Khaw PT. Recent advances in trabeculectomy technique. Curr Opin Ophthalmol 2005;16:107-113.

21. Kozlov VI, Bagrov SN, Anisimova SY, et al, Nonpenetrating deep sclerectomy with collagen. Eye Microsurgery (in Russian), 1990;3:44-46.

22. Sanchez E, Schnyder CC, Sickenberg M, et al. Deep sclerectomy: results with and without collagen implant. Int Ophthalmol 1997;20:157-162.

23. Vaudaux ID, Uffer S, Mermoud A. Aqueous dynamics after deep sclerectomy; in vitro study. Ophthalmic Pract 1998;16:204-209.

24. Sanchez E, Schnyder CC, Mermoud A. Résultats comparatives de la sclérectomie profonde transformée en trabéculectomie et de la trabéculectomie classique. Klin Monatsbl Augenheilkd 1997;210:261-264.

25. Shaarawy T, Mansouri K, Schnyder C, et al. Long-term results of deep sclerectomy with collagen implant. J Cat Refract Surg 2004;30:1225-31. 
26. Shaarawy T, Mermoud A. Deep sclerectomy in one eye vs deep sclerectomy with collagen implant in the contralateral eye of the same patient: long-term follow-up. Eye 2005;19:298302.

27. Shaarawy T, Nguyen C, Schnyder C, et al. Comparative study between deep sclerectomy with and without collagen implant: long term follow up. Br J Ophthalmol 2004;88:95-8.

28. Mermoud A, Schnyder CC, Sickenberg M, Chiou AG, Hédiguer SE, Faggioni R. Comparison of deep sclerectomy with collagen implant and trabeculectomy in open-angle glaucoma. J Cataract Refract Surg 1999;25:323-31.

29. El Sayyad F, Helal M, El-Kholify H, Khalil M, El-Maghraby A. Nonpenetrating deep sclerectomy versus trabeculectomy in bilateral primary open-angle glaucoma. Ophthalmology $2000 ; 107: 1671-4$.

30. Chiselita $\mathrm{D}$. Non-penetrating deep sclerectomy versus trabeculectomy in primary open-angle glaucoma surgery. Eye 2001;15:197-201.

31. Cillino S, Di Pace F, Casuccio A, Cillino G, Lodato G. Deep sclerectomy versus trabeculectomy with low-dosage mitomycin C: four-year follow-up. Ophthalmologica. $2008 ; 222: 81-7$.

32. Sharma T, Salmon JF. Ten-year outcomes in newly diagnosed glaucoma patients: mortality and visual function. Br J Ophthalmol 2007;91:1282-1284. 


\section{Legends for figures}

Figure 1.

A) One third thickness $(300 \mu \mathrm{m})$ limbus based superficial scleral flap measuring $5 \times 5 \mathrm{~mm}$ is dissected and extended $1 \mathrm{~mm}$ further into clear cornea. A rectangle or square of deep sclera is dissected leaving a thin layer of deep sclera covering the choroid on the posterior plane. Schlemm's canal is exposed.

B) Descemet's membrane exposure is performed with a ruby knife.

C) The deep sclera is carefully extended further into the corneal stroma to expose at least 1-2 mm of Descemet's membrane.

D) The deep sclera is excised using a diamond blade.

E) A toothed forceps is peeling off the inner wall of the Schlemm's canal.

F) The collagen implant is placed radially (in the center of the deep sclerectomy dissection) and secured with a single 10.0 nylon suture to the thin remaining scleral layer.

Figure 2. Mean postoperative intraocular pressure (IOP) evolution. $(\mathrm{p}<0.005)$. Preop indicates preoperative, and $n$ the number of patients; $M$, month; $Y$, year. Bar: SD.

Figure 3. Mean number of antiglaucoma medications per patient before and after surgery. $(p<0.05)$. Preop indicates preoperative, and $n$ the number of patients. Bar: SD.

Figure 4. Cumulative complete and qualified long-term success rate using Kaplan-Meier survival curve; $\mathrm{n}$ indicates the number at risk.

Figure 5. Mean postoperative Snellen best corrected visual acuity (BCVA) evolution. $(\mathrm{p}=0.23)$. Preop indicates preoperative, and $\mathrm{n}$ the number of patients; $\mathrm{M}$, month; $\mathrm{Y}$, year. Bar: SD. 
Table 1. Preoperative glaucoma diagnosis

\begin{tabular}{|l|l|l|}
\hline Type of Glaucomas & $\begin{array}{l}\text { Number of } \\
\text { patients }\end{array}$ & $\begin{array}{l}\text { Percentage } \\
(\%)\end{array}$ \\
\hline Primary open angle glaucoma & 53 & 50.5 \\
\hline Pseudoexfoliative glaucoma & 22 & 20.9 \\
\hline Pseudophakic glaucoma & 14 & 13.3 \\
\hline Normal tension glaucoma & 5 & 4.8 \\
\hline Pigmentary glaucoma & 4 & 3.8 \\
\hline Aphakic glaucoma & 2 & 1.9 \\
\hline Other glaucoma $*$ & 5 & 4.8 \\
\hline
\end{tabular}

*Other glaucoma includes 1 inflammatory glaucoma (Posner-Schlossman Syndrome), 2 traumatic glaucomas, 1 corticosteroïd induced glaucoma and 1 iridocorneal dysgenesia. 
Table 2. Definitions of postoperative complications and additional procedures

\begin{tabular}{|c|l|}
\hline Complications & Definition \\
\hline Hyphaema & Erythrocytes in the anterior chamber \\
\hline Hypotony & Postoperative IOP $<4$ mmHg for $>2$ weeks \\
\hline Shallow anterior chamber & Iridocorneal touch in the periphery \\
\hline Flat anterior chamber & Lens-cornea touch \\
\hline Anterior chamber inflammation & Flare or/and cells seen in the anterior chamber \\
\hline Choroidal detachment & $\begin{array}{l}\text { Seen in the peripheral retina using an indirect } \\
\text { ophthalmoscope }\end{array}$ \\
\hline Surgery-induced cataract & $\begin{array}{l}\text { Rapid decrease (1 month) in the visual acuity; } \\
\text { mainly cortical opacities }\end{array}$ \\
\hline Progressive cataract & $\begin{array}{l}\text { Slow progressive decrease in visual acuity of }>2 \\
\text { lines (Snellen chart), essentially due to nuclear } \\
\text { sclerosis }\end{array}$ \\
\hline $\begin{array}{l}\text { Subconjunctiva injections of } 5 \mathrm{mg} \\
\text { of 5-fluorouracil (administered in } \\
\text { the lower quadrant opposite to the } \\
\text { deep sclerectomy) }\end{array}$ & $\begin{array}{l}\text { When filtering blebs were encysted or showed } \\
\text { signs of fibrosis }\end{array}$ \\
\hline \begin{tabular}{l} 
Needling \\
\hline Nd: YAG laser Goniopuncture
\end{tabular} & $\begin{array}{l}\text { When filtering blebs were encysted or showed } \\
\text { signs of fibrosis }\end{array}$ \\
\hline $\begin{array}{l}\text { When filtration through the trabeculo-Descemet's } \\
\text { insufficient reflected by an increasing IOP }>18 \\
\text { mmHg }\end{array}$ \\
\hline
\end{tabular}


Table 3. Postoperative complications after DSCI

\begin{tabular}{|l|l|l|}
\hline Postoperative complications & $\begin{array}{l}\text { Number of } \\
\text { patients }\end{array}$ & Percentage (\%) \\
\hline Flat anterior chamber & 0 & 0 \\
\hline Hyphaema & 9 & 8.6 \\
\hline Dellen & 6 & 5.7 \\
\hline Transient hypotony & 2 & 1.9 \\
\hline Bleb leakage & 9 & 8.6 \\
\hline Subtle choroidal detachment & 8 & 7.6 \\
\hline Malignant Glaucoma & 1 & 0.9 \\
\hline Surgery related cataract & 0 & 0 \\
\hline Encysted bleb & 24 & 22.8 \\
\hline Bleb fibrosis & 12 & 11.4 \\
\hline Encysted bleb + bleb fibrosis & 3 & 2.8 \\
\hline
\end{tabular}




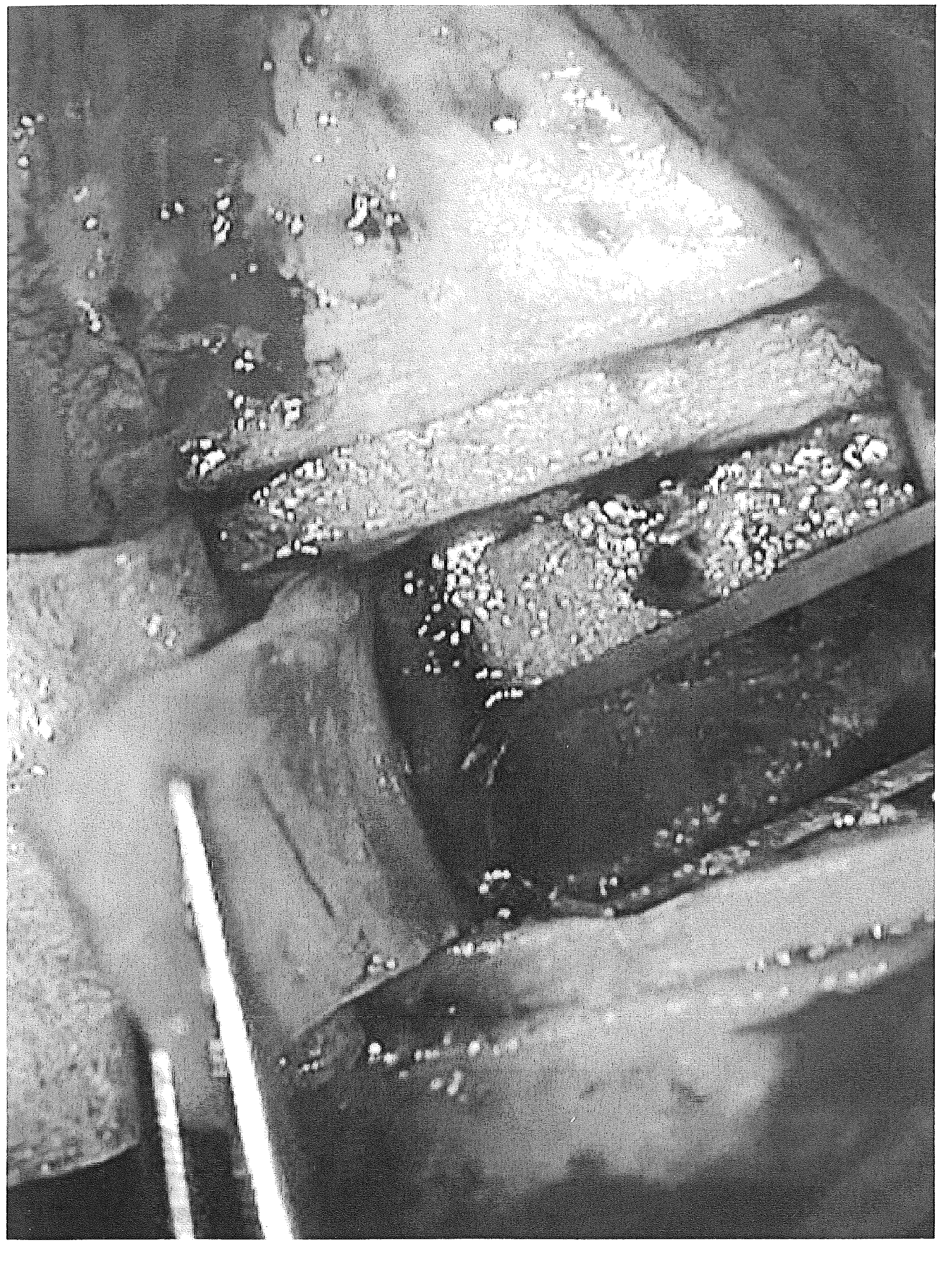




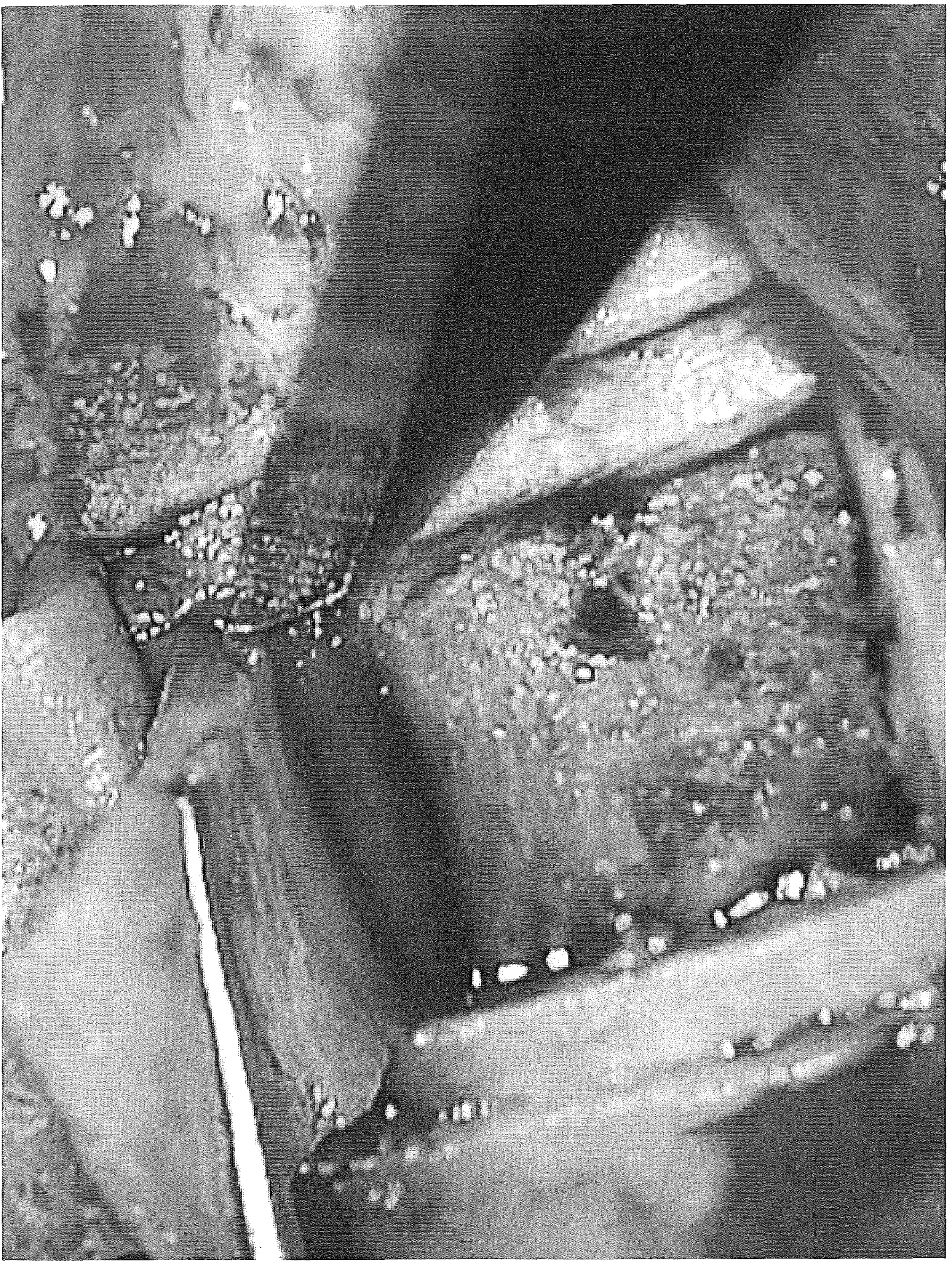




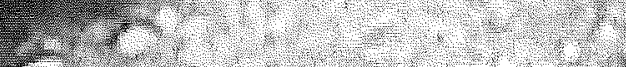
$\sqrt{10}$

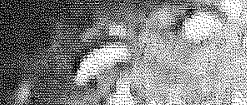

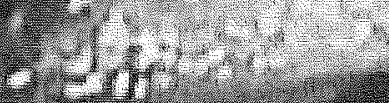
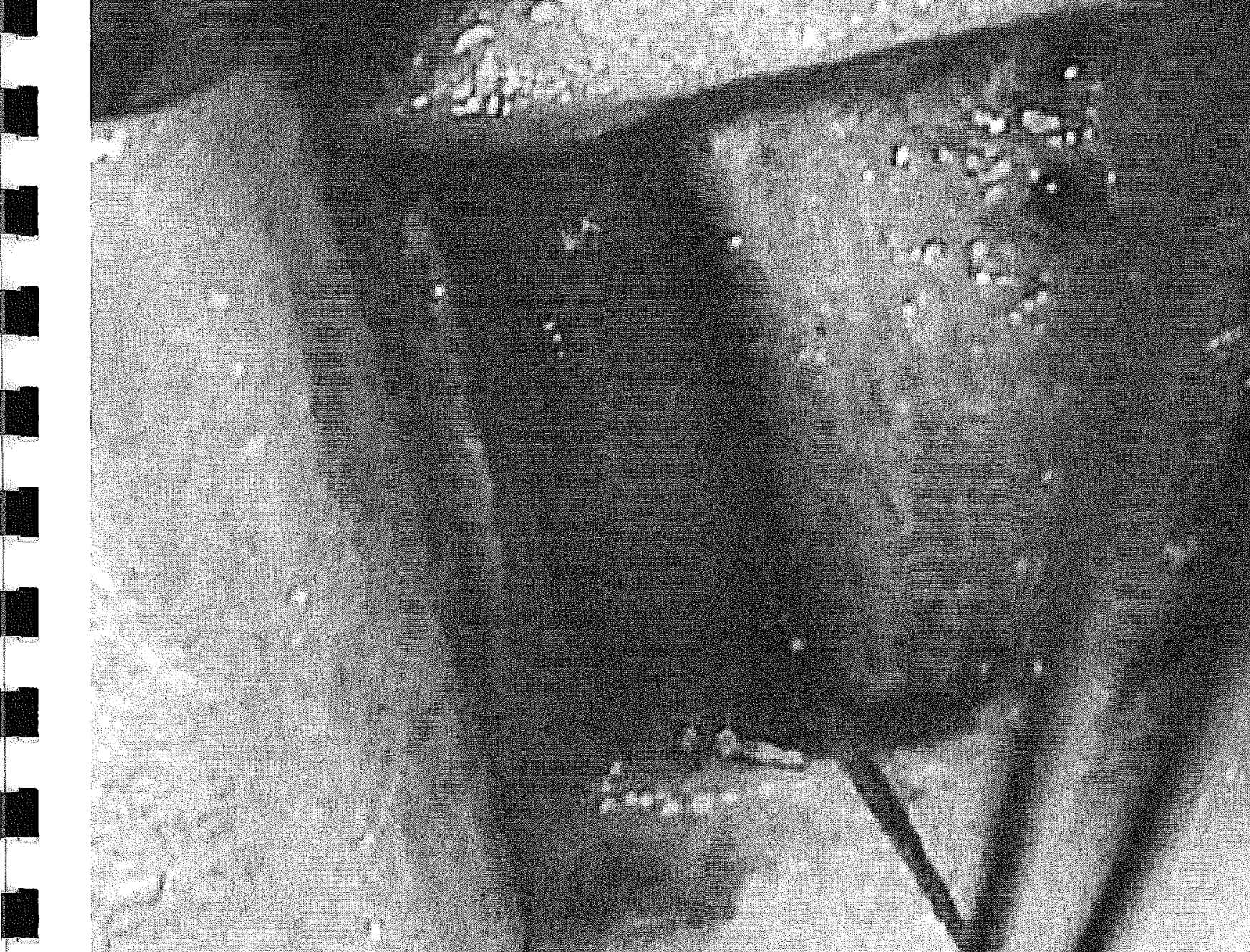

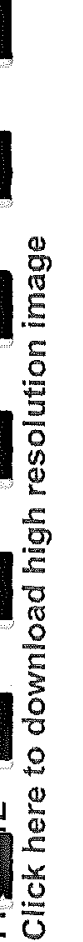
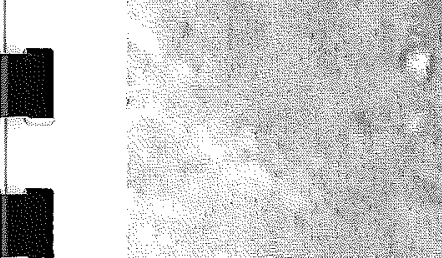

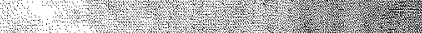
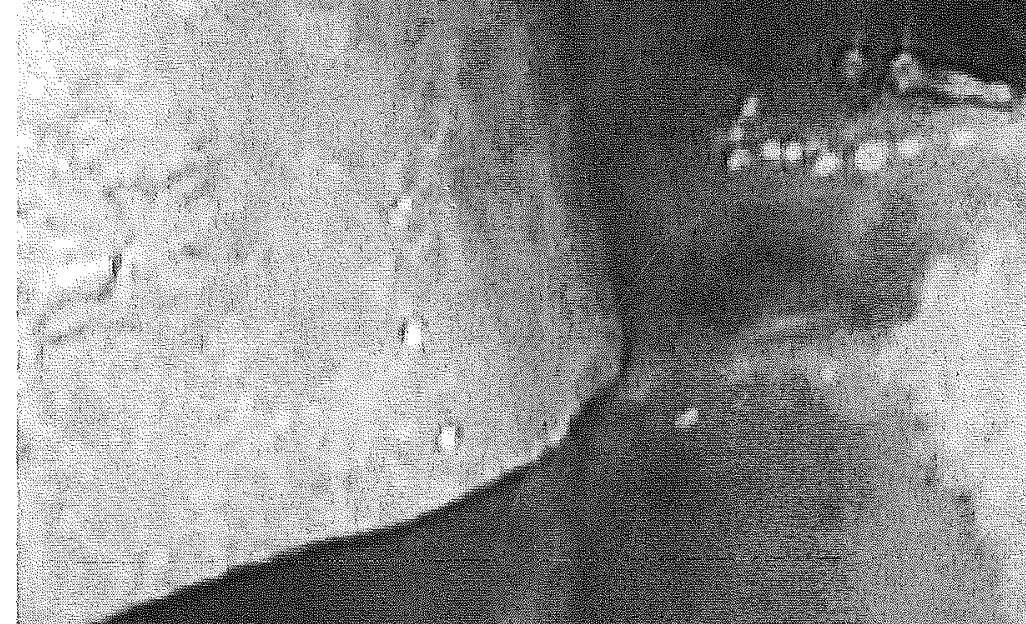

$-3^{3}=$ 


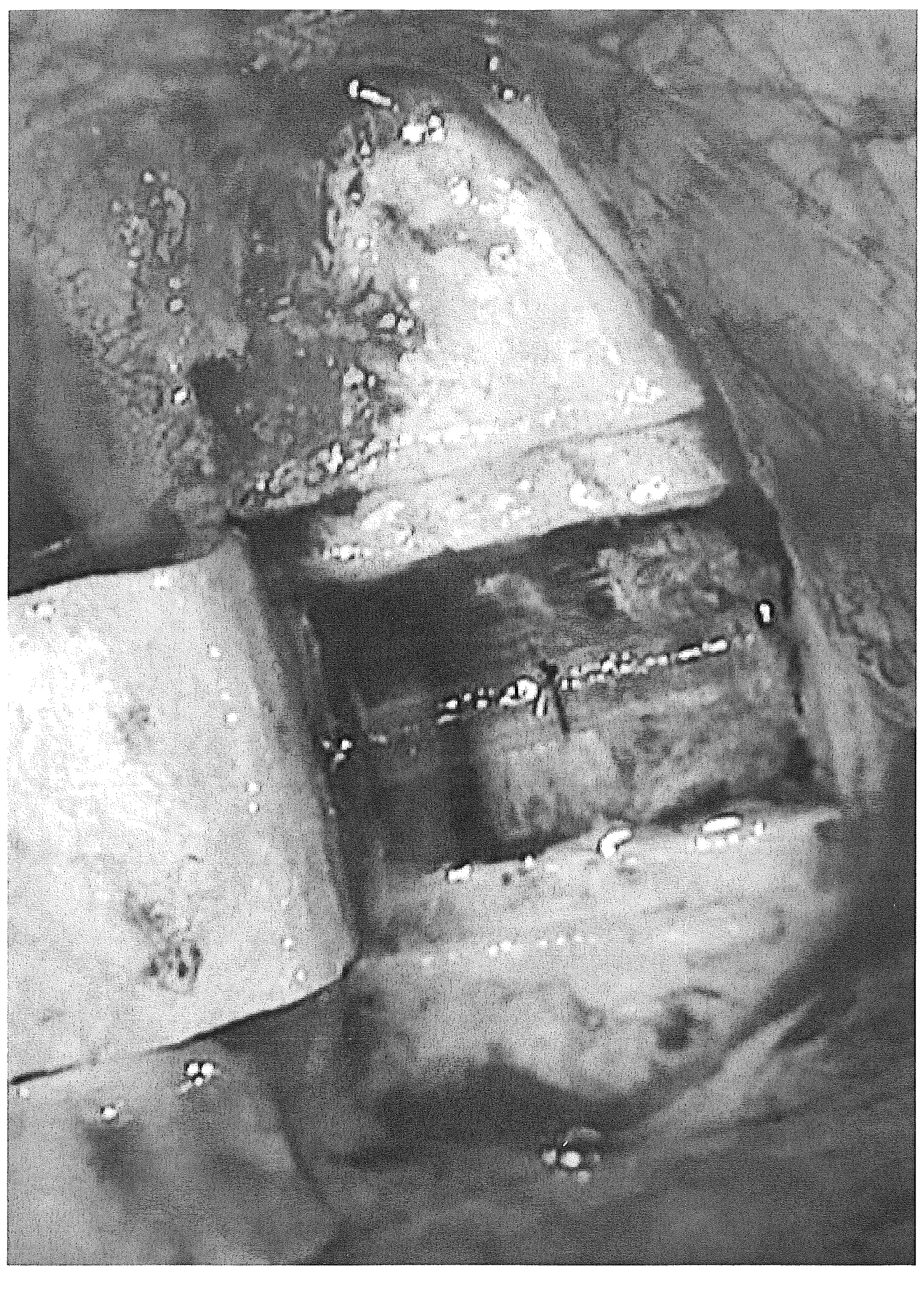




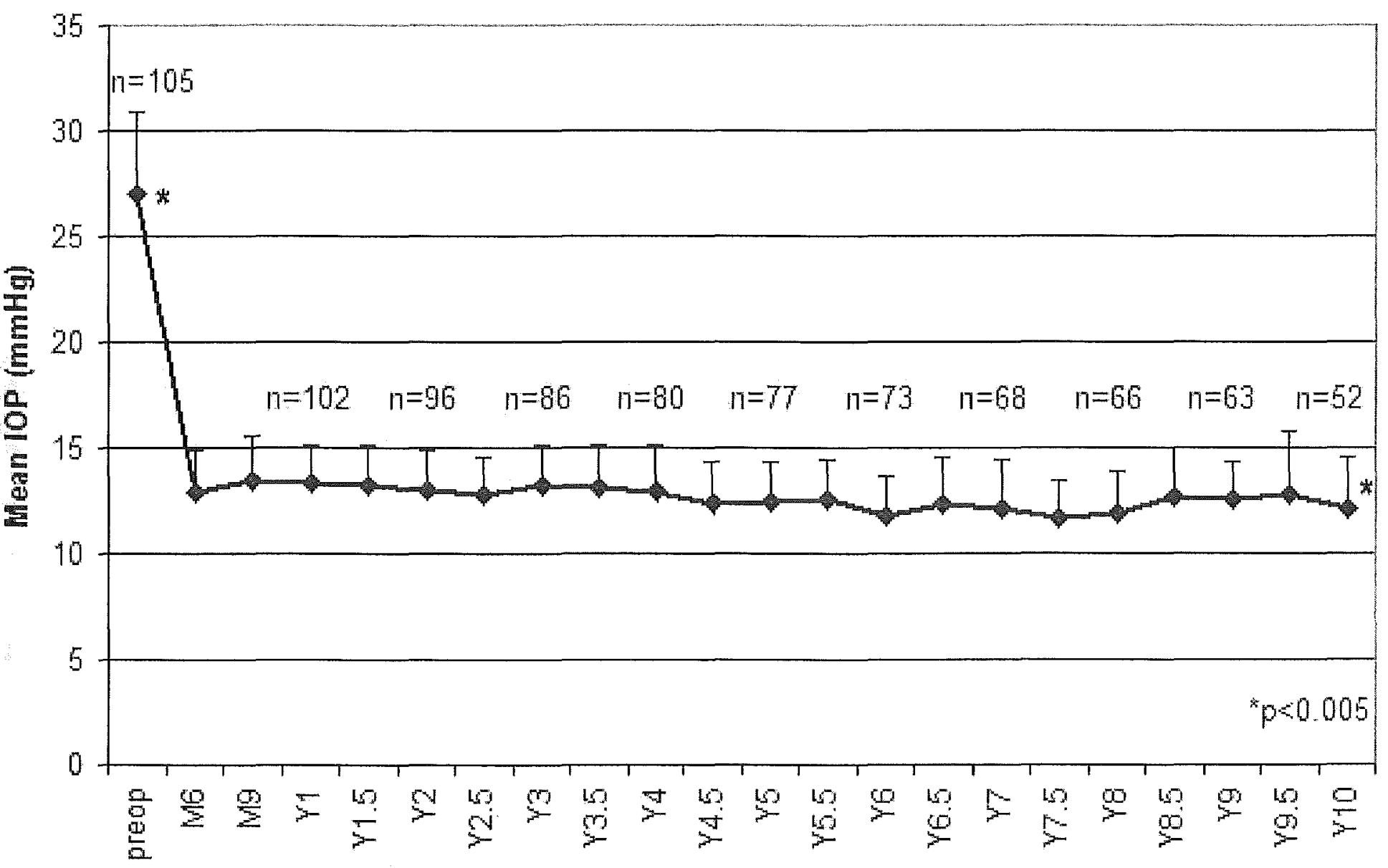

Time 


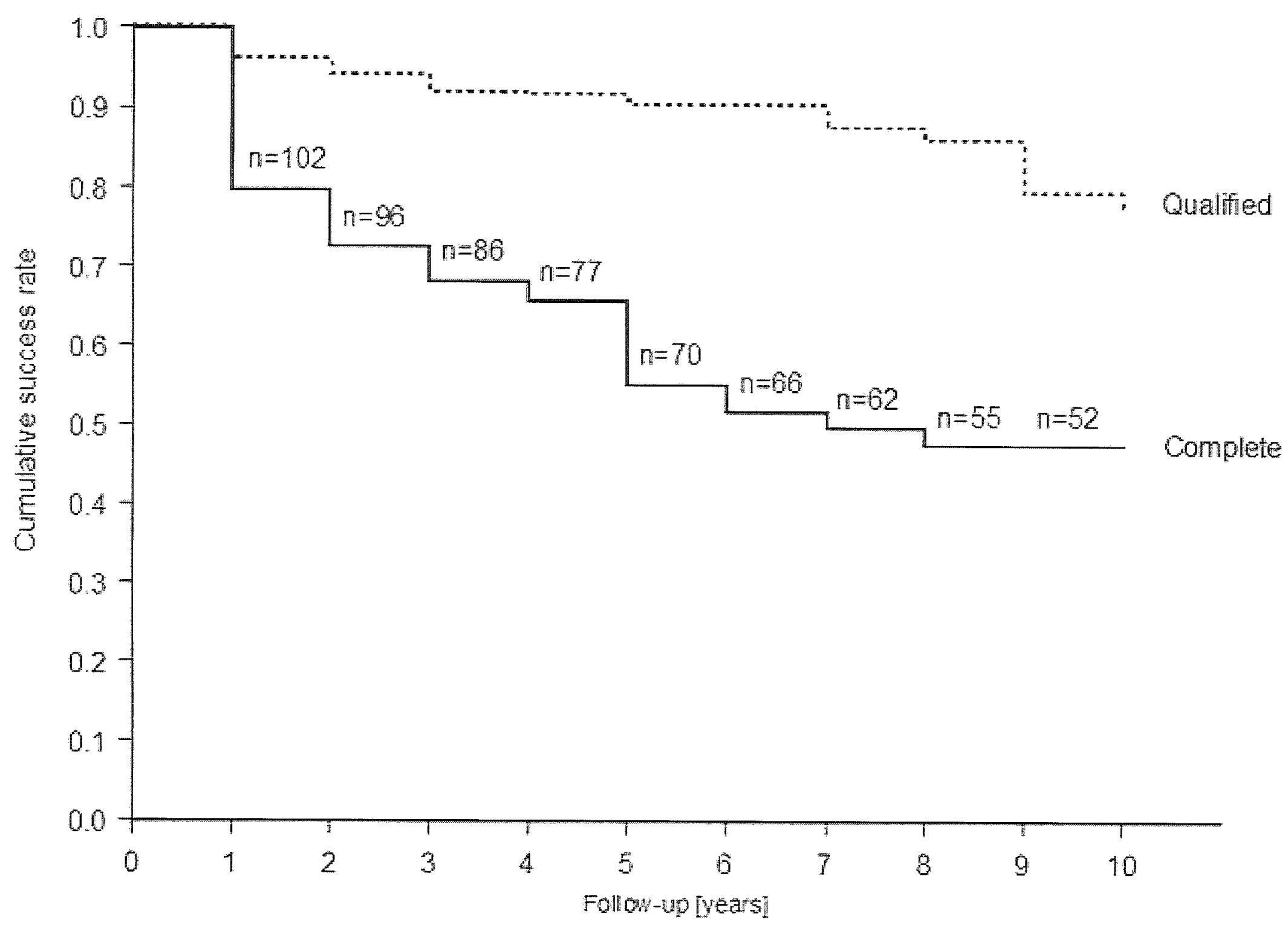


